\title{
Obesity and Placental Function
}

\author{
Leslie Myatt, PhD, FRCOG ${ }^{2}$ Alina Maloyan, $\mathrm{PhD}^{1}$ \\ ${ }^{1}$ Center for Pregnancy and Newborn Research, University of Texas \\ Health Science Center San Antonio, San Antonio, Texas \\ 2 Department of Obstetrics and Gynecology, Oregon Health and \\ Science University, Portland, Oregon
}

Address for correspondence Leslie Myatt, PhD, FRCOG, Department of Obstetrics and Gynecology, Oregon Health and Science University, 3181 S.W. Sam Jackson Park Rd., Portland, OR 97239-3098 (e-mail: myattl@ohsu.edu).

Semin Reprod Med 2016;34:42-49

\begin{abstract}
Keywords

- placenta

- obesity

- inflammation

- mitochondria

- oxidative stress

- epigenetics

An increasing number of women of reproductive age are obese which affects the continuum of pregnancy and is associated with an increased incidence of adverse maternal and fetal outcomes, including preeclampsia, preterm birth, stillbirth, congenital anomalies, and macrosomia. Maternal obesity is associated with an increased incidence of metabolic and cardiovascular disease later in life in the mother and in the offspring who are developmentally programed by the obese pregnancy environment. The placenta transduces and mediates the effect of the adverse maternal environment to the fetus. The obese maternal environment is characterized by hyperlipidemia and an exaggerated state of inflammation and oxidative stress compared with normal pregnancy. Heightened inflammation and oxidative/nitrative stress are found in the placenta in association with placental dysfunction. We have described reduced mitochondrial respiration and ATP generation in trophoblast isolated from placentas of obese compared with lean women, again suggesting compromised placental function. In utero development exhibits sexual dimorphism with the male fetus at greater risk of poor outcome. We have shown dimorphism in inflammation-mediated regulation of trophoblast mitochondrial respiration. There is also increasing evidence that the obese in utero environment may cause epigenetic changes in placenta leading to altered function.
\end{abstract}

Obesity is a global health concern among adults and children of both sexes and has major societal and economic costs. The number of women of reproductive age who are overweight (body mass index $[\mathrm{BMI}]=25-30 \mathrm{~kg} / \mathrm{m}^{2}$ ) or obese $\left(\mathrm{BMI}>30 \mathrm{~kg} / \mathrm{m}^{2}\right.$ ) continues to increase, with the incidence of obesity among pregnant women now estimated at between 18.5 and $38.3 \%{ }^{1}$ The economic cost of obesity in pregnancy is greater than $\$ 100$ million annually. ${ }^{2}$ Maternal obesity affects the continuum of pregnancy. Fertility and fecundity rates are lower among overweight and obese women, in spontaneous conception as well as in artificial reproductive techniques. ${ }^{1}$ During pregnancy, these women are more susceptible to hypertensive disorders, gestational diabetes, respiratory complications, and thromboembolic events. ${ }^{1,3-6}$ While unknown cause remains the most common contributor to stillbirth with
$40 \%$ of these cases occurring in late gestation, ${ }^{7}$ up to $25 \%$ of stillbirths between 37 and 42 weeks of gestation are perhaps due to obesity. ${ }^{8}$ Indeed obesity may explain the increased morbidity including the increased risk ( 2.8 fold) of late stillbirth, particularly in males, in such pregnancies. ${ }^{9}$ Overweight women also have a slower labor progression rate; higher rates of cesarean deliveries ${ }^{10}$; and more surgery-related complications such as difficult spinal, epidural, or general anesthesia, wound infection, and endometritis. ${ }^{1,3}$ From the fetal and newborn perspective, complications include congenital malformations, ${ }^{11}$ largefor-gestational-age infants, ${ }^{12}$ intrauterine growth restriction, stillbirth, and shoulder dystocia. Finally, the effects are not confined to pregnancy alone. Obese and also gestational diabetic women have greater rates of type 2 diabetes $^{13}$ and cardiovascular disease later in life.
Issue Theme Implantation: TrophoblastEndometrial Interactions; Guest Editor, Jared C. Robins, MD
Copyright $\odot 2016$ by Thieme Medical Publishers, Inc., 333 Seventh Avenue, New York, NY 10001, USA. Tel: +1(212) 584-4662. 


\section{Obesity and Developmental Programing}

By virtue of its location and roles at the interface between the mother and fetus, the placenta is the key regulator of fetal growth and development. ${ }^{14}$ The placenta not only conveys the maternal metabolic environment to the fetus but can also become both a target and a source of pathogenic factors affecting the fetus. ${ }^{15}$ Developmental programing occurs when the normal developmental pattern is disrupted by inappropriate or ill-timed signals reaching the fetus or neonate which is then set on an altered developmental trajectory that can lead to disease in adult life. ${ }^{16} \mathrm{~A}$ large body of evidence ${ }^{17}$ shows that an adverse or altered intrauterine or early postnatal environment, including obesity, can program for disease in adult life including cardiovascular disease, obesity and metabolic syndrome, diabetes, osteoporosis, cancer, and disorders of the hypothalamic/pituitary/adrenal axis. ${ }^{1,3,18-20}$ Hence, while obese women may have babies within the normal birth weight range, with normal sized placentas and apparently a normal outcome there may be a programing effect on the fetus that is only revealed subsequently. While it is clear that maternal obesity programs the fetus, the mechanism and physiological consequences of the adverse metabolic and inflammatory environment of obesity for placental function and fetal development are just now being elucidated.

\section{Sexual Dimorphism and Developmental Programing}

It is clear that male and female fetuses respond differently to the adverse intrauterine environment. This may then relate to their risk of developing disease in adult life where differences in incidence of various diseases are clearly documented. Even in "normal" pregnancy and development, there is a sexually dimorphic effect. Male fetuses grow faster and are usually larger than females. ${ }^{21}$ However, male fetuses are at much higher risk during pregnancy and show greater incidences of preterm birth, preterm premature rupture of membranes, placenta previa, lagging lung development, greater incidence of macrosomia with maternal glucose intolerance, and more late stillbirths associated with pregestational diabetes. ${ }^{22}$ The female neonate can more readily adapt to ex utero life even when delivered in a highly immature state at midgestation, an effect possibly mediated by in utero adaptations to an adverse environment prior to delivery. ${ }^{23}$ The male fetus is claimed "to live dangerously in the womb" to maximize its growth potential but with consequent high risk when faced with additional adverse events. ${ }^{22}$ It is likely that there is a complex interaction between the adverse environment of obesity and fetal sex.

\section{Sexual Dimorphism and the Placenta}

The placenta is a fetal tissue that shows sexual dimorphism. Microarray analysis revealed distinct sexually dimorphic profiles of gene expression in the human placenta; in particular immune genes were expressed at higher level in female placenta compared with male. ${ }^{24}$ Gene expression in the placenta also responds to maternal inflammatory status in sex-dependent manner. ${ }^{25}$ Expression of 59 genes was changed in the placenta of women with asthma versus no asthma with a female fetus compared with only 6 genes changed in those with asthma with a male fetus. ${ }^{26}$ Some of these genes were associated with growth, inflammatory, and immune pathways. Changes in diet provide distinctive signature of sexually dimorphic genes in placenta with expression generally higher in genes in female than in male placenta. ${ }^{27}$ The male placenta has higher toll-like receptor 4 (TLR4) expression and a greater production of tumor necrosis factor (TNF)- $\alpha$ in response to lipopolysaccharide (LPS) than the female placenta, which can underlie the propensity to preterm birth in males. ${ }^{28}$ The mechanisms of sexual dimorphism in placenta with obesity remain unstudied; however, evidence from other complicated pregnancies links sex differences to gonadal steroids. Women with preeclampsia have increased plasma testosterone levels compared with those of healthy pregnant women, with significantly higher levels in male- than in female-bearing preeclamptic pregnancies. ${ }^{29} \mathrm{At}$ the same time, the placental levels of aromatase, a ratelimiting enzyme converting androgens to estrogens, varied depending on fetal sex: it was much higher in the preeclamptic placentas with female than male fetuses. ${ }^{30}$ Interestingly, aromatase can be downregulated by TNF $\alpha$, hypoxia, insulin, and leptin, which mirror the actual conditions of the placenta in the context of maternal obesity. ${ }^{31-34}$

\section{Inflammation in Pregnancy with Obesity}

Pregnancy per se is an inflammatory state. ${ }^{35}$ This is enhanced in pregnancies complicated by obesity, ${ }^{36}$ where increased concentrations of inflammatory cytokines can be seen in maternal plasma ${ }^{37}$ and the placenta. ${ }^{38}$ The increased placental inflammation in obese pregnancy may be stimulated by endotoxin, ${ }^{36}$ lipids, ${ }^{39}$ reactive oxygen species (ROS), ${ }^{40}$ or oxidized lipids. ${ }^{41}$ Chronic low-grade inflammation in obese women prior to pregnancy initiates a cascade of events which translate into an inflammatory in utero environment. Significant accumulation of subsets of macrophages has been shown in placentas from obese patients resulting in production of proinflammatory cytokines and adipokines including interleukin-6 (IL-6), leptin, TNF- $\alpha$, monocyte chemotactic protein 1, and TLR4. ${ }^{42-44}$ Uncontrolled placental inflammation leads to the impairment of overall placental function such as increased free fatty acid (FFA) delivery to the fetal circulation, which is expected to alter fetal growth and development. ${ }^{45}$ We found that TNF- $\alpha$, used to simulate the inflammatory milieu of obesity, decreases trophoblast mitochondrial respiration but in a sexually dimorphic manner. The effect is seen only in trophoblasts of a female placenta and is mediated by the transcription factor NFKB1. ${ }^{46}$

\section{Effect of Obesity on Maternal and Placental Metabolism in Pregnancy}

Pregnancy is a state of profound metabolic changes characterized by increased fat mass, insulin resistance, low-grade inflammation, ${ }^{35}$ and mild hyperlipidemia, ${ }^{47}$ where phospholipids, total LDL and HDL cholesterol, and triglycerides all 
increase. The metabolic changes become exacerbated with pregravid obesity. ${ }^{48}$ Obese pregnant women are characterized by high levels of FFA, higher circulating levels of leptin, TNF- $\alpha$, IL-1, IL-6, IL-8, oxidative stress, and reduced levels of adiponectin. $^{49}$

The placenta, particularly syncytiotrophoblast, has tremendous oxygen consumption ${ }^{50}$ and metabolic activity, the energy for which is derived from ATP mainly generated by oxidative phosphorylation in mitochondria. Glucose was traditionally thought of as the major (if not sole) substrate for energy generation in fetus and placenta. ${ }^{51}$ However, the placenta does not appear to utilize anaerobic glycolysis to generate energy during periods of anoxia. ${ }^{52}$ Work in the past 10 years has shown that the placenta can generate energy from fatty acids ${ }^{53}$ via fatty acid oxidation (FAO). ${ }^{54}$ Long chain fatty acids necessary for placental FAO are abundant in maternal plasma in late gestation but are markedly increased with obesity and thought to play a role in insulin resistance. ${ }^{55}$ Deficiencies in placenta of enzymes involved in FAO lead to accumulation of toxic long chain metabolites and are associated with maternal HELLP syndrome and with preeclampsia. ${ }^{56}$ Saturated fatty acids, palmitate and stearate, activate inflammatory signaling pathways via interaction with TLRs and via secretion of cytokines including TNF- $\alpha$, Il- $1 \beta$, and IL- $6 .{ }^{57}$ We find significantly increased level of TNF- $\alpha$ in the placenta of female fetuses of obese women. ${ }^{46}$ Fatty acids also reduce mitochondrial function through induction of proinflammatory cytokines, and chronically elevated fatty acids are associated with increased production of reactive oxygen and nitrogen species. ${ }^{58}$ There has not been an investigation of FAO in the placenta of obese pregnancies, nor has it been studied in relation to circulating maternal saturated or unsaturated fatty acids, inflammatory cytokines, or oxidative stress or to fetal outcomes.

\section{Free Fatty Acids and Lipid Transport in Placenta during Maternal Obesity}

Although maternal hyperglycemia has long been associated with increased fetal growth, ${ }^{59}$ maternal triglycerides also contribute with aberrant fetal growth seen with gestational diabetes mellitus (GDM) despite good glucose control. Indeed in multivariate analysis, increased birth weight positively correlates only with hypertriglyceridemia in women with GDM. ${ }^{60}$ However, such studies have not been performed in pregnancies complicated by obesity alone, nor in relation to fetal adiposity.

Placental uptake of FFAs from the maternal circulation provides fatty acids both for placental metabolism and delivery to the fetus. ${ }^{61}$ Cells involved in active lipid trafficking express discrete fatty acid binding proteins (FABP), implicated in cellular uptake and transport of fatty acids and coordination of metabolic and inflammatory pathways. ${ }^{62,63}$ FABP1, FABP3, FABP4, FABP5, and FABP plasma membranes are expressed in human trophoblasts. ${ }^{64}$ Maternal obesity can alter lipid content and increase the expression of FABP4 in trophoblasts. ${ }^{65}$ An ovine model of maternal obesity showed significantly higher concentration of FFA in the fetal circulation of obese ewes at midgestation than in control ewes. ${ }^{45}$ In addition, the level of peroxisome proliferator-activated receptor gamma which is known to be essential for placental development and placental uptake of fatty acids was found to be activated in the placenta of obese ewes. ${ }^{61}$ As fatty acids are ligands for TLR4, which drives the inflammatory response, 66 it was postulated that excessive fatty acids in the fetal circulation in the setting of maternal obesity would activate TLR4 signaling, resulting in inflammation of fetal tissues.

\section{Placental Oxidative/Nitrative Stress and Obesity}

Pregnancy is a state of oxidative stress. Mitochondria are the major source of ROS under physiologic conditions. Increased metabolic activity in placental mitochondria and the reduced scavenging power of antioxidants may be responsible for rapid ROS generation by different placental cell types. ${ }^{67,68}$ At the same time, mitochondrial function itself can be compromised by severe and/or prolonged oxidative stress. Oxidative inactivation of mitochondrial DNA polymerase gamma could slow down mitochondrial DNA (mtDNA) replication and eventually lead to inhibition of oxidative phosphorylation. ${ }^{69}$ The placenta can also produce nitric oxide (NO.) and this molecule in combination with excess superoxide can result in the production of peroxynitrite $\left(\mathrm{ONOO}^{-}\right)$, leading to nitrative stress. Peroxynitrite is a powerful prooxidant that can modify tyrosine residues within a protein sequence to give nitrotyrosine, or protein nitration. Covalent modification of proteins by nitration may be a physiologic regulatory mechanism in redox regulation for signaling pathways. ${ }^{70}$ Nitrotyrosine residues have been demonstrated in the placenta of pregnancies complicated by preeclampsia, ${ }^{71}$ pregestational diabetes, ${ }^{72}$ and chronic hypoxia at high altitude. ${ }^{73}$ We have previously shown nitration of several proteins in the human placenta, and demonstrated that the extent of nitration is increased in obese compared with lean and overweight placentas. ${ }^{40}$ Koeck et $\mathrm{al}^{74}$ provided evidence for rapid and selective oxygen-regulated protein tyrosine denitration/nitration in the mitochondria. Nitrated proteins can be eliminated from mitochondria during hypoxia/anoxia and regenerated during reoxygenation. This nitration/denitration in mitochondria may affect cellular energy and redox homeostasis and therefore cell and tissue viability.

\section{Placental Mitochondrial Energetics and Obesity}

As stated previously, the placenta can generate energy from fatty acids ${ }^{53}$ following FAO and generation of acetyl CoA. We have shown that with increasing maternal adiposity, there is a significant fall in mitochondrial respiration by oxidative phosphorylation and in ATP generation in the placenta ${ }^{75}$ that is not compensated for by glycolysis. In galactose-containing medium, the trophoblast from obese pregnancies cannot increase oxidative phosphorylation, that is, they show metabolic inflexibility. This would suggest that with obesity, 
the generation of acetyl CoA by FAO is compromised. Fatty acids also reduce mitochondrial function perhaps via proinflammatory cytokines and/or increased production of reactive oxygen and nitrogen species. ${ }^{58}$ In turn, mitochondrial dysfunction can lead to a reduction in mitochondrial FAO. ${ }^{76}$ Saturated fatty acids (palmitate, stearate) may be more damaging while unsaturated fatty acids (oleic, DHA) may be beneficial.

Mitochondria generate most of the cell's supply of ATP, used as a source of chemical energy which are also involved in a range of other processes, such as signaling, cellular differentiation, apoptosis and programed cell death, control of the cell cycle and cell growth, regulation of the membrane potential, regulation of cellular metabolism, and steroid synthesis. Damage, reduced content, and functional capacity of mitochondria are involved in neurodegenerative and cardiovascular diseases, ${ }^{77}$ obesity and diabetes. ${ }^{78,79}$ Diminished FAO and greater dependence on glucose for ATP synthesis, ${ }^{80}$ ectopic lipid accumulation in skeletal muscle, the liver, and other cells ${ }^{81}$ and low basal ATP concentrations ${ }^{43}$ are seen with obesity. Mitochondrial oxidative capacity is decreased in skeletal muscle of obese individuals, ${ }^{76}$ in the kidney of highfat diet (HFD)-fed mice, ${ }^{82}$ as well as in the liver and the heart of ob/ob mice. ${ }^{83,84}$ An isoenergetic HFD in healthy young men for only 3 days was sufficient to reduce the expression of genes involved in mitochondrial complexes I and II, and mitochondrial carriers. ${ }^{85}$ While oxidative stress and mitochondrial dysfunction are often proposed as mechanisms mediating dysfunction in various organs in obesity models, little data are available for the placenta.

\section{Sexual Dimorphism in the Effect of Inflammation on Placental Mitochondria}

MicroRNAs (miRNAs) are conserved, regulatory molecules that have an important role in the posttranscriptional regulation of target gene expression by promoting mRNA instability or translational inhibition. ${ }^{86}$ MicroRNA-210, which has been traditionally linked to hypoxia, ${ }^{87}$ targets and decreases activity of mitochondrial subunits in placen$\mathrm{ta}^{88}$ hence reducing cellular respiration. We have shown that expression of miR-210 was significantly increased in placentas of obese and overweight women conceived with female, but not male, fetuses compared with female placentas of lean women. ${ }^{46}$ We also demonstrated increased TNF- $\alpha$ in female but not male placentas of overweight and obese women, and that via NFKB1 (p50) signaling this resulted in activation of miR-210 expression. Chromatin immunoprecipitation assay showed that NFkB1 binds to placental miR-210 promoter in a fetal sex-dependent manner such that female but not male trophoblast treated with TNF- $\alpha$ showed overexpression of miR-210, reduction of mitochondrial target genes, and decreased mitochondrial respiration. Overall, our data suggest that the inflammatory intrauterine environment associated with maternal obesity induces an NFKB1mediated increase in miR-210 in a fetal sex-dependent manner, leading to inhibition of mitochondrial respiration and placental dysfunction in the placentas of female fetuses.
We propose that impaired mitochondrial function in placenta and hence altered placental metabolism can evoke changes in the fetus and may potentially link maternal obesity to metabolic and cardiovascular disease in the offspring.

We have recently shown that increasing maternal adiposity is associated with increased generation of ROS and decreased mitochondrial respiration in the placenta. ${ }^{75}$ Total antioxidant capacity and activity of superoxide dismutase are significantly greater in the lean male placentas than in lean female placentas or placentas of either sex from an obese mother (unpublished data, L. Myatt PhD, 2015), that is, there is sexual dimorphism and an effect of obesity. The connection of oxidative stress to mitochondrial dysfunction has refocused use of antioxidants in pregnancy toward alleviation of mitochondrial dysfunction. Selenium is a trace element necessary for normal cellular function and which protects trophoblast mitochondria against oxidative $\operatorname{stress}^{89}$ by upregulating activity of antioxidant enzymes glutathione peroxidases, thioredoxin reductases, and iodothyronine deiodinases. $^{90}$

\section{Obesity and Epigenetics in the Placenta}

Epigenetics describes heritable changes in gene expression that are not mediated by DNA sequence alterations ${ }^{91}$ but are susceptible to environmental influences. ${ }^{92}$ Several diverse factors epigenetically regulate genes, including age, lifestyle, inflammation, gender, genotype, stress, nutrition, metabolism, drugs, and infection. ${ }^{93}$ Epigenetic information is conveyed in mammals via a synergistic interaction between mitotically heritable patterns of DNA methylation ${ }^{94}$ and chromatin structure. ${ }^{95}$ Local chromatin conformation regulates specific methylation patterns to control gene transcription. ${ }^{96}$ Epigenetic mechanisms have been postulated to have a role in developmental programing of obesity and type 2 diabetes in offspring by the intrauterine environment ${ }^{97}$ and may therefore also regulate placental function. There are several mechanisms that regulate epigenetic changes.

Gene expression can be altered via posttranslational covalent modifications of chromatin by histone methylation or acetylation which determines accessibility to transcription factors ${ }^{98}$ leading to transcriptionally repressive or permissive chromatin structures. ${ }^{99,100}$ Repressive histone modifications seem to confer short-term, flexible silencing important for developmental plasticity, whereas DNA methylation is believed to be a more stable, long-term silencing mechanism. ${ }^{101}$ Differential histone modification occurs in a genderspecific manner, ${ }^{102}$ and in primates ${ }^{103}$ and rats, ${ }^{104}$ consumption of a maternal HFD gave altered histone modifications of fetal hepatic genes accompanied by alterations in hepatic gene expression. There is, however, relatively little data ${ }^{105}$ on histone modification in the human placenta with pregnancy complications.

Hypermethylation of DNA in promoter regions typically is associated with transcriptional repression of genes, whereas hypomethylation leads to gene activity. ${ }^{106}$ Global DNA methylation in the placenta increases with advancing gestational age, ${ }^{107}$ but with greater interindividual variation in the third 
trimester suggesting environmental factors may influence methylation, gene expression, and function of the placenta. Variations in DNA methylation profiles in the term placenta are seen in relation to pregnancy outcome (reviewed in Koukoura et $\mathrm{al}^{108}$ ). Recently, a novel modification DNA hydroxymethylation has been described. ${ }^{109}$ Ten-eleven translocase (TET) enzymes convert $5 \mathrm{mC}$ to $5 \mathrm{hmC}$. Although $5 \mathrm{mC}$ is repressive, $5 \mathrm{hmC}$ is permissive for gene expression. Therefore, the balance of $5 \mathrm{mC}$ to $5 \mathrm{hmc}$ at particular CpGs may control gene expression. Alpha ketoglutarate $(\alpha K G)$ and ascorbate are cofactors for TET enzymes, suggesting a link between cellular metabolism and epigenetic regulation of cellular activity as $\alpha \mathrm{KG}$ is produced in the citric acid cycle. Maternal nutritional status may alter the epigenetic state of the fetal genome and imprinted gene expression. ${ }^{110}$ Hyperglycemia induces demethylation of specific cytosines throughout the genome ${ }^{111}$ with altered gene expression.

In mammalian genomes, DNA methyltransferase (DNMT) enzymes mediate the transfer of methyl groups from S-adenosylmethionine to cytosine, ${ }^{112}$ establish and maintain DNA methylation patterns at specific regions of the genome, and contribute to gene regulation. DNMT1 is primarily a maintenance methyltransferase preserving methylation patterns during cell division, while DNMT3 enzymes are responsible for de novo methylation. The metabolic/inflammatory milieu of obesity increases DNMT3a expression of DNMT3a in adipose tissue of obese mice ${ }^{113}$ and correlates with gene suppression. There is little data available on DNMTs in human placenta.

\section{The Influence of Nutrition and the Metabolic Environment on Epigenetic Modifications}

While there is increasing evidence from other tissues that metabolic regulation of epigenetic mechanisms occurs, it is relatively unstudied in placenta. Tight regulation of epigenetic changes is essential especially in the early phase of gestation where global DNA demethylation in the zygote is seen but may subsequently be influenced by the maternal metabolic environment. Chromatin-modifying enzymes including DNMTs can sense and respond to alterations to the nutritional environment through their effects on intermediary metabolites. ${ }^{114}$ Differences in DNA methylation have been reported in individuals exposed to famine during the Dutch Hunger Winter. ${ }^{115,116}$ In later life, the epigenome appears to be capable of responding to changes in nutrients including deficiencies in methyl donors, ${ }^{117}$ folic acid supplementation, ${ }^{118}$ as well as fat ${ }^{119}$ and caloric restriction. ${ }^{120}$ The dramatic changes in methylation seen in early gestation and the relative hypomethylation of the placenta suggest it to be susceptible to dietary influences. Recently, intrauterine caloric restriction in mice, which programs male offspring for glucose intolerance, increased fat mass, and hypercholesterolemia, gave a significant decrease in overall methylation throughout the placental genome. ${ }^{121}$ The level of demethylation was greater in placentas of male mice than in placentas of female mice and imprinted genes appeared to be more susceptible to methylation changes.

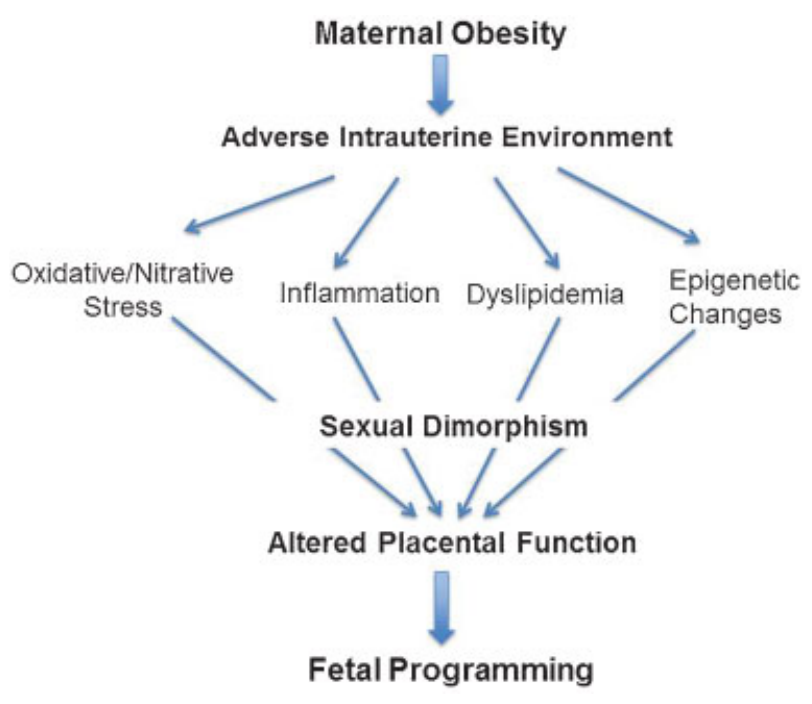

Fig. 1 Mechanisms linking maternal obesity to placental dysfunction and developmental programing.

\section{Conclusion}

The intrauterine environment found in the obese women is associated with poor pregnancy outcomes and importantly with programing the fetus for disease in later life. This effect is mediated via the placenta (-Fig. 1), which displays altered function and compromised energetics related to the obese environment of hyperlipidemia, heightened inflammation, and oxidative stress. Evidence that the metabolic environment of obesity causes epigenetic changes is accumulating and needs to be studied in the placenta to link cellular metabolism to changes in gene expression and cellular function. There is also an overarching effect of fetal and placental sex, which now needs to be considered when studying placental function.

\section{References}

1 Yogev Y, Catalano PM. Pregnancy and obesity. Obstet Gynecol Clin North Am 2009;36(2):285-300, viii

2 Trasande L, Lee M, Liu Y, Weitzman M, Savitz D. Incremental charges, costs, and length of stay associated with obesity as a secondary diagnosis among pregnant women. Med Care 2009; 47(10):1046-1052

3 Reece EA. Obesity, diabetes, and links to congenital defects: a review of the evidence and recommendations for intervention. J Matern Fetal Neonatal Med 2008;21(3):173-180

4 Vasudevan C, Renfrew M, McGuire W. Fetal and perinatal consequences of maternal obesity. Arch Dis Child Fetal Neonatal Ed 2011;96(5):F378-F382

5 Baeten JM, Bukusi EA, Lambe M. Pregnancy complications and outcomes among overweight and obese nulliparous women. Am J Public Health 2001;91(3):436-440

6 Sebire NJ, Jolly M, Harris JP, et al. Maternal obesity and pregnancy outcome: a study of 287,213 pregnancies in London. Int J Obes Relat Metab Disord 2001;25(8):1175-1182

7 Wou K, Ouellet MP, Chen MF, Brown RN. Comparison of the aetiology of stillbirth over five decades in a single centre: a retrospective study. BMJ Open 2014;4(6):e004635 
8 Yao R, Ananth CV, Park BY, Pereira L, Plante LA; Perinatal Research Consortium. Obesity and the risk of stillbirth: a population-based cohort study. Am J Obstet Gynecol 2014; 210(5):457.e1-457.e9

9 Aune D, Saugstad OD, Henriksen T, Tonstad S. Maternal body mass index and the risk of fetal death, stillbirth, and infant death: a systematic review and meta-analysis. JAMA 2014;311(15): 1536-1546

10 Ehrenberg HM, Durnwald CP, Catalano P, Mercer BM. The influence of obesity and diabetes on the risk of cesarean delivery. Am J Obstet Gynecol 2004;191(3):969-974

11 Watkins ML, Botto LD. Maternal prepregnancy weight and congenital heart defects in offspring. Epidemiology 2001;12(4): 439-446

12 Ehrenberg HM, Mercer BM, Catalano PM. The influence of obesity and diabetes on the prevalence of macrosomia. Am J Obstet Gynecol 2004;191(3):964-968

13 Kim C, Newton KM, Knopp RH. Gestational diabetes and the incidence of type 2 diabetes: a systematic review. Diabetes Care 2002;25(10):1862-1868

14 Myatt L. Placental adaptive responses and fetal programming. J Physiol 2006;572(Pt 1):25-30

15 Liguori A, D’Armiento FP, Palagiano A, et al. Effect of gestational hypercholesterolaemia on omental vasoreactivity, placental enzyme activity and transplacental passage of normal and oxidised fatty acids. BJOG 2007;114(12):1547-1556

16 Barker DJ. The origins of the developmental origins theory. J Intern Med 2007;261(5):412-417

17 Barker DJ, Bagby SP, Hanson MA. Mechanisms of disease: in utero programming in the pathogenesis of hypertension. Nat Clin Pract Nephrol 2006;2(12):700-707

18 Chu SY, Kim SY, Lau J, et al. Maternal obesity and risk of stillbirth: a metaanalysis. Am J Obstet Gynecol 2007;197(3):223-228

19 Frias AE, Morgan TK, Evans AE, et al. Maternal high-fat diet disturbs uteroplacental hemodynamics and increases the frequency of stillbirth in a nonhuman primate model of excess nutrition. Endocrinology 2011;152(6):2456-2464

20 Rogers LK, Velten M. Maternal inflammation, growth retardation, and preterm birth: insights into adult cardiovascular disease. Life Sci $2011 ; 89(13-14): 417-421$

21 Clifton VL. Review: Sex and the human placenta: mediating differential strategies of fetal growth and survival. Placenta 2010;31(Suppl):S33-S39

22 Eriksson JG, Kajantie E, Osmond C, Thornburg K, Barker DJ. Boys live dangerously in the womb. Am J Hum Biol 2010;22(3): 330-335

23 Stark MJ, Wright IM, Clifton VL. Sex-specific alterations in placental 11 beta-hydroxysteroid dehydrogenase 2 activity and early postnatal clinical course following antenatal betamethasone. Am J Physiol Regul Integr Comp Physiol 2009;297(2):R510-R514

24 Sood R, Zehnder JL, Druzin ML, Brown PO. Gene expression patterns in human placenta. Proc Natl Acad Sci USA 2006; 103(14):5478-5483

25 Scott NM, Hodyl NA, Murphy VE, et al. Placental cytokine expression covaries with maternal asthma severity and fetal sex. J Immunol 2009;182(3):1411-1420

26 Osei-Kumah A, Smith R, Jurisica I, Caniggia I, Clifton VL. Sexspecific differences in placental global gene expression in pregnancies complicated by asthma. Placenta 2011;32(8): 570-578

27 Mao J, Zhang X, Sieli PT, Falduto MT, Torres KE, Rosenfeld CS. Contrasting effects of different maternal diets on sexually dimorphic gene expression in the murine placenta. Proc Natl Acad Sci USA 2010;107(12):5557-5562

28 Yeganegi M, Leung CG, Martins A, et al. Lactobacillus rhamnosus GR-1 stimulates colony-stimulating factor 3 (granulocyte) (CSF3) output in placental trophoblast cells in a fetal sex-dependent manner. Biol Reprod 2011;84(1):18-25
29 Steier JA, Ulstein M, Myking OL. Human chorionic gonadotropin and testosterone in normal and preeclamptic pregnancies in relation to fetal sex. Obstet Gynecol 2002;100(3):552-556

30 Sathishkumar K, Balakrishnan M, Chinnathambi V, Chauhan M, Hankins GD, Yallampalli C. Fetal sex-related dysregulation in testosterone production and their receptor expression in the human placenta with preeclampsia. J Perinatol 2012;32(5): 328-335

31 Díaz L, Noyola-Martínez N, Barrera D, et al. Calcitriol inhibits TNFalpha-induced inflammatory cytokines in human trophoblasts. J Reprod Immunol 2009;81(1):17-24

32 Jiang B, Kamat A, Mendelson CR. Hypoxia prevents induction of aromatase expression in human trophoblast cells in culture: potential inhibitory role of the hypoxia-inducible transcription factor Mash-2 (mammalian achaete-scute homologous protein2). Mol Endocrinol 2000;14(10):1661-1673

33 Acromite MT, Mantzoros CS, Leach RE, Hurwitz J, Dorey LG. Androgens in preeclampsia. Am J Obstet Gynecol 1999;180; (1, Pt 1):60-63

34 Christensen A, Froyshov D, Fylling P. Hormone and enzyme assays in pregnancy. IV. The human chorionic somatomammotrophin, placental cystine-aminopeptidase, progesterone and the urinary oestrogens in pregnancies complicated with essential hypertension, mild or severe pre-eclampsia. Acta Endocrinol (Copenh) 1974;77(2):344-355

35 Stewart FM, Freeman DJ, Ramsay JE, Greer IA, Caslake M, Ferrell WR. Longitudinal assessment of maternal endothelial function and markers of inflammation and placental function throughout pregnancy in lean and obese mothers. J Clin Endocrinol Metab 2007;92(3):969-975

36 Basu S, Haghiac M, Surace P, et al. Pregravid obesity associates with increased maternal endotoxemia and metabolic inflammation. Obesity (Silver Spring) 2011;19(3):476-482

37 Aye IL, Lager S, Ramirez VI, et al. Increasing maternal body mass index is associated with systemic inflammation in the mother and the activation of distinct placental inflammatory pathways. Biol Reprod 2014;90(6):129

38 Roberts KA, Riley SC, Reynolds RM, et al. Placental structure and inflammation in pregnancies associated with obesity. Placenta 2011;32(3):247-254

39 Pathmaperuma AN, Maña P, Cheung SN, et al. Fatty acids alter glycerolipid metabolism and induce lipid droplet formation, syncytialisation and cytokine production in human trophoblasts with minimal glucose effect or interaction. Placenta 2010;31(3): 230-239

40 Roberts VH, Smith J, McLea SA, Heizer AB, Richardson JL, Myatt L. Effect of increasing maternal body mass index on oxidative and nitrative stress in the human placenta. Placenta 2009;30(2): 169-175

41 Aye IL, Waddell BJ, Mark PJ, Keelan JA. Oxysterols exert proinflammatory effects in placental trophoblasts via TLR4-dependent, cholesterol-sensitive activation of NF-KB. Mol Hum Reprod 2012;18(7):341-353

42 Challier JC, Basu S, Bintein T, et al. Obesity in pregnancy stimulates macrophage accumulation and inflammation in the placenta. Placenta 2008;29(3):274-281

43 Kelley DE, He J, Menshikova EV, Ritov VB. Dysfunction of mitochondria in human skeletal muscle in type 2 diabetes. Diabetes 2002;51(10):2944-2950

44 Lager S, Jansson N, Olsson AL, Wennergren M, Jansson T, Powell TL. Effect of IL- 6 and TNF- $\alpha$ on fatty acid uptake in cultured human primary trophoblast cells. Placenta 2011;32(2):121-127

45 Zhu MJ, Du M, Nathanielsz PW, Ford SP. Maternal obesity upregulates inflammatory signaling pathways and enhances cytokine expression in the mid-gestation sheep placenta. Placenta 2010;31(5):387-391

46 Muralimanoharan S, Guo C, Myatt L, Maloyan A. Sexual dimorphism in miR-210 expression and mitochondrial dysfunction in 
the placenta with maternal obesity. Int J Obes 2015;39(8): 1274-1281

47 Ghio A, Bertolotto A, Resi V, Volpe L, Di Cianni G. Triglyceride metabolism in pregnancy. Adv Clin Chem 2011;55:133-153

48 Catalano PM, Huston L, Amini SB, Kalhan SC. Longitudinal changes in glucose metabolism during pregnancy in obese women with normal glucose tolerance and gestational diabetes mellitus. Am J Obstet Gynecol 1999;180(4):903-916

49 Aviram A, Hod M, Yogev Y. Maternal obesity: implications for pregnancy outcome and long-term risks-a link to maternal nutrition. Int J Gynaecol Obstet 2011;115(Suppl 1):S6-S10

50 Carter AM. Placental oxygen consumption. Part I: in vivo studiesa review. Placenta 2000;21(Suppl A):S31-S37

51 Jones CT, Rolph TP. Metabolism during fetal life: a functional assessment of metabolic development. Physiol Rev 1985;65(2): 357-430

52 Bloxam DL, Bobinski PM. Energy metabolism and glycolysis in the human placenta during ischaemia and in normal labour. Placenta 1984;5(5):381-394

53 Shekhawat P, Bennett MJ, Sadovsky Y, Nelson DM, Rakheja D, Strauss AW. Human placenta metabolizes fatty acids: implications for fetal fatty acid oxidation disorders and maternal liver diseases. Am J Physiol Endocrinol Metab 2003;284(6): E1098-E1105

54 Oey NA, den Boer ME, Ruiter JP, et al. High activity of fatty acid oxidation enzymes in human placenta: implications for fetalmaternal disease. J Inherit Metab Dis 2003;26(4):385-392

55 Shulman GI. Cellular mechanisms of insulin resistance. J Clin Invest 2000;106(2):171-176

56 Bartha JL, Visiedo F, Fernández-Deudero A, Bugatto F, Perdomo G. Decreased mitochondrial fatty acid oxidation in placentas from women with preeclampsia. Placenta 2012;33(2):132-134

57 Håversen L, Danielsson KN, Fogelstrand L, Wiklund O. Induction of proinflammatory cytokines by long-chain saturated fatty acids in human macrophages. Atherosclerosis 2009;202(2):382-393

58 Lambertucci RH, Hirabara SM, Silveira LdosR, Levada-Pires AC, Curi R, Pithon-Curi TC. Palmitate increases superoxide production through mitochondrial electron transport chain and NADPH oxidase activity in skeletal muscle cells. J Cell Physiol 2008; 216(3):796-804

59 Metzger BE, Persson B, Lowe LP, et al; HAPO Study Cooperative Research Group. Hyperglycemia and adverse pregnancy outcome study: neonatal glycemia. Pediatrics 2010;126(6): e1545-e1552

60 Whyte K, Kelly H, O’Dwyer V, Gibbs M, O'Higgins A, Turner MJ. Offspring birth weight and maternal fasting lipids in women screened for gestational diabetes mellitus (GDM). Eur J Obstet Gynecol Reprod Biol 2013;170(1):67-70

61 Xu Y, Wang Q Cook TJ, Knipp GT. Effect of placental fatty acid metabolism and regulation by peroxisome proliferator activated receptor on pregnancy and fetal outcomes. J Pharm Sci 2007; 96(10):2582-2606

62 Storch J, Corsico B. The emerging functions and mechanisms of mammalian fatty acid-binding proteins. Annu Rev Nutr 2008; 28:73-95

63 Furuhashi M, Hotamisligil GS. Fatty acid-binding proteins: role in metabolic diseases and potential as drug targets. Nat Rev Drug Discov 2008;7(6):489-503

64 Biron-Shental T, Schaiff WT, Ratajczak CK, Bildirici I, Nelson DM, Sadovsky Y. Hypoxia regulates the expression of fatty acidbinding proteins in primary term human trophoblasts. Am J Obstet Gynecol 2007;197(5):516.e1-516.e6

65 Scifres CM, Chen B, Nelson DM, Sadovsky Y. Fatty acid binding protein 4 regulates intracellular lipid accumulation in human trophoblasts. J Clin Endocrinol Metab 2011;96(7):E1083-E1091

66 Shi H, Kokoeva MV, Inouye K, Tzameli I, Yin H, Flier JS. TLR4 links innate immunity and fatty acid-induced insulin resistance. J Clin Invest 2006;116(11):3015-3025
67 Llurba E, Gratacós E, Martín-Gallán P, Cabero L, Dominguez C. A comprehensive study of oxidative stress and antioxidant status in preeclampsia and normal pregnancy. Free Radic Biol Med 2004; 37(4):557-570

68 Watson AL, Skepper JN, Jauniaux E, Burton GJ. Susceptibility of human placental syncytiotrophoblastic mitochondria to oxygenmediated damage in relation to gestational age. J Clin Endocrinol Metab 1998;83(5):1697-1705

69 Graziewicz MA, Day BJ, Copeland WC. The mitochondrial DNA polymerase as a target of oxidative damage. Nucleic Acids Res 2002;30(13):2817-2824

70 Seo J, Lee KJ. Post-translational modifications and their biological functions: proteomic analysis and systematic approaches. J Biochem Mol Biol 2004;37(1):35-44

71 Kossenjans W, Eis A, Sahay R, Brockman D, Myatt L. Role of peroxynitrite in altered fetal-placental vascular reactivity in diabetes or preeclampsia. Am J Physiol Heart Circ Physiol 2000; 278(4):H1311-H1319

72 Lyall F, Gibson JL, Greer IA, Brockman DE, Eis AL, Myatt L. Increased nitrotyrosine in the diabetic placenta: evidence for oxidative stress. Diabetes Care 1998;21(10):1753-1758

73 Zamudio S, Kovalenko O, Vanderlelie J, et al. Chronic hypoxia in vivo reduces placental oxidative stress. Placenta 2007;28(8-9): 846-853

74 Koeck T, Stuehr DJ, Aulak KS. Mitochondria and regulated tyrosine nitration. Biochem Soc Trans 2005;33(Pt 6):1399-1403

75 Mele J, Muralimanoharan S, Maloyan A, Myatt L. Impaired mitochondrial function in human placenta with increased maternal adiposity. Am J Physiol Endocrinol Metab 2014;307(5): E419-E425

76 Lowell BB, Shulman GI. Mitochondrial dysfunction and type 2 diabetes. Science 2005;307(5708):384-387

77 Pieczenik SR, Neustadt J. Mitochondrial dysfunction and molecular pathways of disease. Exp Mol Pathol 2007;83(1): 84-92

78 Højlund K, Wrzesinski K, Larsen PM, et al. Proteome analysis reveals phosphorylation of ATP synthase beta -subunit in human skeletal muscle and proteins with potential roles in type 2 diabetes. J Biol Chem 2003;278(12):10436-10442

79 Ritov VB, Menshikova EV, He J, Ferrell RE, Goodpaster BH, Kelley DE. Deficiency of subsarcolemmal mitochondria in obesity and type 2 diabetes. Diabetes 2005;54(1):8-14

80 Zurlo F, Lillioja S, Esposito-Del Puente A, et al. Low ratio of fat to carbohydrate oxidation as predictor of weight gain: study of 24-h RQ. Am J Physiol 1990;259(5, Pt 1):E650-E657

81 Goodpaster BH, Theriault R, Watkins SC, Kelley DE. Intramuscular lipid content is increased in obesity and decreased by weight loss. Metabolism 2000;49(4):467-472

82 Ruggiero C, Ehrenshaft M, Cleland E, Stadler K. High-fat diet induces an initial adaptation of mitochondrial bioenergetics in the kidney despite evident oxidative stress and mitochondrial ROS production. Am J Physiol Endocrinol Metab 2011;300(6): E1047-E1058

83 Boudina S, Sena S, O'Neill BT, Tathireddy P, Young ME, Abel ED. Reduced mitochondrial oxidative capacity and increased mitochondrial uncoupling impair myocardial energetics in obesity. Circulation 2005;112(17):2686-2695

84 Chavin KD, Yang S, Lin HZ, et al. Obesity induces expression of uncoupling protein-2 in hepatocytes and promotes liver ATP depletion. J Biol Chem 1999;274(9):5692-5700

85 Sparks LM, Xie H, Koza RA, et al. A high-fat diet coordinately downregulates genes required for mitochondrial oxidative phosphorylation in skeletal muscle. Diabetes 2005;54(7): 1926-1933

86 Inui M, Martello G, Piccolo S. MicroRNA control of signal transduction. Nat Rev Mol Cell Biol 2010;11(4):252-263

87 Chan YC, Banerjee J, Choi SY, Sen CK. miR-210: the master hypoxamir. Microcirculation 2012;19(3):215-223 
88 Muralimanoharan S, Maloyan A, Mele J, Guo C, Myatt LG, Myatt L. MIR-210 modulates mitochondrial respiration in placenta with preeclampsia. Placenta 2012;33(10):816-823

89 Khera A, Vanderlelie JJ, Perkins AV. Selenium supplementation protects trophoblast cells from mitochondrial oxidative stress. Placenta 2013;34(7):594-598

90 Panee J, Stoytcheva ZR, Liu W, Berry MJ. Selenoprotein H is a redox-sensing high mobility group family DNA-binding protein that up-regulates genes involved in glutathione synthesis and phase II detoxification. J Biol Chem 2007;282(33):23759-23765

91 Bird A. DNA methylation patterns and epigenetic memory. Genes Dev 2002;16(1):6-21

92 Petronis A. Human morbid genetics revisited: relevance of epigenetics. Trends Genet 2001;17(3):142-146

93 Alegría-Torres JA, Baccarelli A, Bollati V. Epigenetics and lifestyle. Epigenomics 2011;3(3):267-277

94 Jones PA, Takai D. The role of DNA methylation in mammalian epigenetics. Science 2001;293(5532):1068-1070

95 Rakyan VK, Preis J, Morgan HD, Whitelaw E. The marks, mechanisms and memory of epigenetic states in mammals. Biochem J 2001;356(Pt 1):1-10

96 Cedar H, Bergman Y. Linking DNA methylation and histone modification: patterns and paradigms. Nat Rev Genet 2009; 10(5):295-304

97 Smith CJ, Ryckman KK. Epigenetic and developmental influences on the risk of obesity, diabetes, and metabolic syndrome. Diabetes Metab Syndr Obes 2015;8:295-302

98 Weinmann AS, Bartley SM, Zhang T, Zhang MQ Farnham PJ. Use of chromatin immunoprecipitation to clone novel E2F target promoters. Mol Cell Biol 2001;21(20):6820-6832

99 Kimura AP, Liebhaber SA, Cooke NE. Epigenetic modifications at the human growth hormone locus predict distinct roles for histone acetylation and methylation in placental gene activation. Mol Endocrinol 2004;18(4):1018-1032

100 Turner BM. Cellular memory and the histone code. Cell 2002; 111(3):285-291

101 Boyer LA, Plath K, Zeitlinger J, et al. Polycomb complexes repress developmental regulators in murine embryonic stem cells. Nature 2006;441(7091):349-353

102 Gagnidze K, Weil ZM, Faustino LC, Schaafsma SM, Pfaff DW. Early histone modifications in the ventromedial hypothalamus and preoptic area following oestradiol administration. J Neuroendocrinol 2013;25(10):939-955

103 Aagaard-Tillery KM, Grove K, Bishop J, et al. Developmental origins of disease and determinants of chromatin structure: maternal diet modifies the primate fetal epigenome. J Mol Endocrinol 2008;41(2):91-102

104 Strakovsky RS, Zhang X, Zhou D, Pan YX. Gestational high fat diet programs hepatic phosphoenolpyruvate carboxykinase gene expression and histone modification in neonatal offspring rats. J Physiol 2011;589(Pt 11):2707-2717

105 Nelissen EC, van Montfoort AP, Dumoulin JC, Evers JL. Epigenetics and the placenta. Hum Reprod Update 2011;17(3):397-417

106 Feinberg AP, Tycko B. The history of cancer epigenetics. Nat Rev Cancer 2004;4(2):143-153

107 Chavan-Gautam P, Sundrani D, Pisal H, Nimbargi V, Mehendale S, Joshi S. Gestation-dependent changes in human placental global DNA methylation levels. Mol Reprod Dev 2011;78(3):150

108 Koukoura O, Sifakis S, Spandidos DA. DNA methylation in the human placenta and fetal growth [review]. Mol Med Rep 2012; 5(4):883-889

109 Branco MR, Ficz G, Reik W. Uncovering the role of 5-hydroxymethylcytosine in the epigenome. Nat Rev Genet 2012;13(1):7-13

110 Haycock PC, Ramsay M. Exposure of mouse embryos to ethanol during preimplantation development: effect on DNA methylation in the h19 imprinting control region. Biol Reprod 2009;81(4): 618-627

111 Pirola L, Balcerczyk A, Tothill RW, et al. Genome-wide analysis distinguishes hyperglycemia regulated epigenetic signatures of primary vascular cells. Genome Res 2011;21(10):1601-1615

112 Goll MG, Bestor TH. Eukaryotic cytosine methyltransferases. Annu Rev Biochem 2005;74:481-514

113 Kamei Y, Suganami T, Ehara T, et al. Increased expression of DNA methyltransferase 3a in obese adipose tissue: studies with transgenic mice. Obesity (Silver Spring) 2010;18(2):314-321

114 Gut P, Verdin E. The nexus of chromatin regulation and intermediary metabolism. Nature 2013;502(7472):489-498

115 Heijmans BT, Tobi EW, Lumey LH, Slagboom PE. The epigenome: archive of the prenatal environment. Epigenetics 2009;4(8): 526-531

116 Tobi EW, Lumey LH, Talens RP, et al. DNA methylation differences after exposure to prenatal famine are common and timing- and sex-specific. Hum Mol Genet 2009;18(21):4046-4053

117 Waterland RA, Lin JR, Smith CA, Jirtle RL. Post-weaning diet affects genomic imprinting at the insulin-like growth factor 2 (Igf2) locus. Hum Mol Genet 2006;15(5):705-716

118 Keyes MK, Jang H, Mason JB, et al. Older age and dietary folate are determinants of genomic and p16-specific DNA methylation in mouse colon. J Nutr 2007;137(7):1713-1717

119 Hoile SP, Irvine NA, Kelsall CJ, et al. Maternal fat intake in rats alters $20: 4 n-6$ and $22: 6 n-3$ status and the epigenetic regulation of Fads2 in offspring liver. J Nutr Biochem 2013;24(7):1213-1220

120 Hass BS, Hart RW, Lu MH, Lyn-Cook BD. Effects of caloric restriction in animals on cellular function, oncogene expression, and DNA methylation in vitro. Mutat Res 1993;295(4-6):281-289

121 Chen PY, Ganguly A, Rubbi L, et al. Intrauterine calorie restriction affects placental DNA methylation and gene expression. Physiol Genomics 2013;45(14):565-576 